\title{
Blue is the new black
}

\author{
Waël C. Hanna, MDCM, MBA, FRCSC
}

From the Department of Thoracic Surgery, McMaster University, Hamilton, Ontario, Canada.

Disclosures: Author has nothing to disclose with regard to commercial support.

Received for publication April 30, 2016; accepted for publication May 2, 2016; available ahead of print June 1, 2016.

Address for reprints: Waël C. Hanna, MDCM, MBA, FRCSC, Department of Thoracic Surgery, McMaster

University, St. Joseph's Healthcare, 50 Charlton Avenue East, Suite T-2105F, Hamilton, ON, Canada

L8N4A6 (E-mail: wael.hanna@me.com).

J Thorac Cardiovasc Surg 2016;152:545

$0022-5223 / \$ 36.00$

Copyright (C) 2016 by The American Association for Thoracic Surgery

http://dx.doi.org/10.1016/j.jtcvs.2016.05.003

In the era of low-dose computed tomography screening for lung cancer, we are frequently facing the problem of indeterminate lung nodules that are too small for biopsy or for detection on positron emission tomography. As a consequence, modern thoracic surgeons must be well versed in minimally invasive localization and excision techniques that can achieve adequate resection margins, minimal morbidity, and maximal preservation of healthy lung tissue. Lin and colleagues ${ }^{1}$ demonstrate the safety and feasibility of a novel technique for localization and resection of small lung nodules using patent blue V (PBV) dye. Although using blue dye to localize lung tumors is not a new concept, PBV presents an advantage over methylene blue because it does not diffuse in the lung parenchyma and has demonstrated a $100 \%$ localization rate in this first series of 196 wedge resections. The authors also demonstrate that PBV injection into the tumor does not influence the ability to make a diagnosis and assess margin status on frozen section, thereby allowing operations to proceed into a lobectomy or segmental resection when malignancy is diagnosed.

The early evidence on sublobar resection for subcentimeter tumors and ground glass opacities demonstrates excellent prognosis with limited lung resection. ${ }^{2,3}$ It is the belief of many that localization followed by thoracoscopic wedge resection is adequate therapy for these preinvasive and minimally invasive lung cancers. The authors ${ }^{1}$ eloquently describe the details of their technique, allowing for easy reproducibility and faster adoption, especially in the case of deep lesions that require parenchymal dissection with cautery before application of the stapler. Unlike microcoil localization, this technique does not require intraoperative fluoroscopy, avoiding the need for a bulky c-arm in the operative field, minimizing radiation exposure, and allowing for direct vision of the target by thoracoscopy rather than on the fluoroscopy monitor. However, like microcoil localization, this has the disadvantage of being a 2-step procedure requiring a skilled interventional radiologist and time in the radiology suite.

Blue is the new black. We are called upon to continue to innovate in this domain by developing safe, effective, and

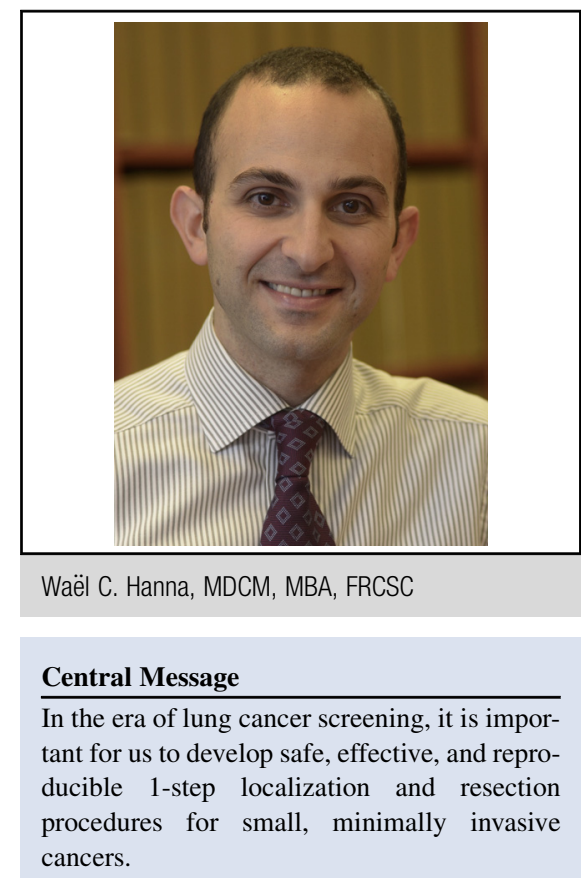

See Article page 535.

easily reproducible 1-step localization-resection procedures that will eliminate the need for radiology and lead to an improved patient experience with streamlined processes. With all the novel work being done in hybrid operating rooms with cone beam computed tomography scans, intracavitary ultrasound, navigational bronchoscopy, and near-infrared fluorescence imaging, detection, localization, and resection of these tumors will become easier and more precise. Therein lies our ultimate challenge: To develop explicit criteria for resection of those lesions. In this series and others, surgery is being performed on lesions as small as $2 \mathrm{~mm}$ in diameter, and one wonders whether they could have been simply observed. It is true that the hardest decision a surgeon has to make is when not to operate.

\section{References}

1. Lin M-W, Tseng Y-H, Lee Y-F, Hsieh M-S, Ko W-C, Chen J-Y, et al Computed tomography-guided patent blue vital dye localization of pulmonary nodules in uniportal thoracoscopy. J Thorac Cardiovasc Surg. 2016;152: 535-44.e2.

2. Kates M, Swanson S, Wisnivesky JP. Survival following lobectomy and limited resection for the treatment of stage I non-small cell lung cancer. Chest. 2011; 139:491-6.

3. Nakamura H, Saji H, Ogata A, Saijo T, Okada S, Kato H. Lung cancer patients showing pure ground-glass opacity on computed tomography are good candidates for wedge resection. Lung Cancer. 2004;44:61-8. 